\title{
Visual Hallucinations as Incidental Negative Effects of Virtual Reality on Parkinson's Disease Patients: A Link with Neurodegeneration?
}

\author{
Giovanni Albani, ${ }_{1}^{1}$ Elisa Pedroli, ${ }^{2}$ Pietro Cipresso, ${ }^{2}$ Daniel Bulla, ${ }^{1}$ Veronica Cimolin, ${ }^{3}$ \\ Astrid Thomas, ${ }^{4}$ Alessandro Mauro, ${ }^{1,5}$ and Giuseppe Riva ${ }^{2,6}$ \\ ${ }^{1}$ Division of Neurology and Neurorehabilitation, Ospedale San Giuseppe, IRCCS Istituto Auxologico Italiano, \\ Via Cadorna 90, Piancavallo, 28824 Verbania, Italy \\ ${ }^{2}$ Applied Technology for Neuro-Psychology Laboratory, IRCCS Istituto Auxologico Italiano, Via Magnasco 2, 20149 Milano, Italy \\ ${ }^{3}$ Department of Electronics, Information and Bioengineering, Politecnico di Milano, Piazza Leonardo da Vinci 32, 20133 Milano, Italy \\ ${ }^{4}$ Department of Neurology, Neuroimaging and Medical Sciences, Università degli Studi "G. d'Annunzio" di Chieti-Pescara, \\ Via dei Vestini 31, 66100 Chieti, Italy \\ ${ }^{5}$ Department of Neuroscience "Rita Levi Montalcini”, Università di Torino, Via Cherasco 15, 10126 Torino, Italy \\ ${ }^{6}$ Department of Psychology, Università Cattolica di Milano, Largo Gemelli 1, 20123 Milano, Italy \\ Correspondence should be addressed to Giovanni Albani; g.albani@auxologico.it
}

Received 3 February 2015; Revised 10 April 2015; Accepted 17 April 2015

Academic Editor: Ivan Bodis-Wollner

Copyright (C) 2015 Giovanni Albani et al. This is an open access article distributed under the Creative Commons Attribution License, which permits unrestricted use, distribution, and reproduction in any medium, provided the original work is properly cited.

We followed up a series of 23 Parkinson's disease (PD) patients who had performed an immersive virtual reality (VR) protocol eight years before. On that occasion, six patients incidentally described visual hallucinations $(\mathrm{VH})$ with occurrences of images not included in the virtual environment. Curiously, in the following years, only these patients reported the appearance of VH later in their clinical history, while the rest of the group did not. Even considering the limited sample size, we may argue that VR immersive systems can induce unpleasant effects in PD patients who are predisposed to a cognitive impairment.

\section{Introduction}

Nowadays, there is an increasing emphasis on the application of technology in the assessment and rehabilitation of neurological diseases and one of these technologies is Virtual Reality (VR). While the literature is limited, there are research programs studying this application specifically in Parkinson's disease (PD). As such, understanding the usefulness, the limitations, and the considerations in the application of the technology is important to both scientific and clinical communities.

In the past few years, strong scientific production has sustained the role played by external cues, such as visual ones, in the multisensory rehabilitative approach to PD [1].

VR technologies combined with treadmill training have been successfully used to ameliorate gait in PD [2-4] by means of an attention-trigger strategy even if, in some cases, a beneficial effect has been described as limited to PD subjects at advanced stages of the disease $[5,6]$.

An occasional negative impact of immersive VR systems on PD patients has been preliminarily reported also for the postural control [7].

We previously $[8,9]$ reported the incidental experience of visual hallucinations $(\mathrm{VH})$ in six of $23 \mathrm{PD}$ patients during immersion in a VR environment in which their virtual actions were tested in comparison with controls.

These observations generate the need to find a clinical reason that may explain the unpleasant effects of VR immersion and help us better understand where the positive effects of VR technology end and the negative ones start.

A relationship between $\mathrm{VH}$ and cognitive impairment in PD has been tentatively established: PD patients with VH 
TABLE 1: Location and characteristics of the hallucinations.

\begin{tabular}{ll}
\hline $\begin{array}{l}\text { Patient } \\
\text { number }\end{array}$ & Location and characteristics of the hallucinations \\
\hline 1 & $\begin{array}{l}\text { In gymnasium: unidentified animals on the wall } \\
\text { In gymnasium: a nest of bees, with the bees flying } \\
\text { around }\end{array}$ \\
3 & $\begin{array}{l}\text { In gymnasium: children sitting at desk } \\
4\end{array}$ \\
$\begin{array}{l}\text { In kitchen: a petrol pump } \\
\text { In supermarket: the woman is mistaken for a policeman }\end{array}$ \\
6 & $\begin{array}{l}\text { In supermarket: unidentified animals on the wall and } \\
\text { on the floor }\end{array}$ \\
\hline
\end{tabular}

show a prolonged choice reaction and a stimulus discrimination deficit [10], as well as an increased risk of dementia [11].

Aim of the present study was to study retrospectively after eight years all the 23 cases who participated in the first VR study [9], in order to verify if that $\mathrm{VH}$ reported during the virtual session may have some correlation with the actual cognitive status.

\section{Methods}

In the 2005 study $[8,9]$, the aim was to evaluate the behaviour of $23 \mathrm{PD}$ patients and 15 healthy controls in VR environments reproducing daily living situations (i.e., supermarket, gym, and kitchen) both after one-hour L-dopa (LD) intake and 12 hours after withdrawal of the LD.

PD patients performed their virtual actions worse than the controls in terms of time of execution, exploration, pointing, and precision in avoiding obstacles. None of the controls complained of any disturbances, such as minor transient effects (nausea or vertigo) or visual abnormalities.

Although none of the participants reported ever having experienced $\mathrm{VH}$, during the off-state virtual session, six PD patients incidentally reported an occurrence of images not included in the virtual environment (Table 1).

The "object" of VH was the same for all patients. According to their descriptions, it seems that in all cases the patient preserved the insight that the hallucinated image was inappropriate at that point of virtual navigation, but they did not appear surprised or worried about this visual experience.

We reviewed the clinical history of all six patients who experienced VH: none had previously reported anything similar to illusions or sensations of presence or passage.

In 2013, we tried to follow up all 23 PD patients of the previous study. According to an agreement between the Local Association of Patients and the Division of Neurology and Neurorehabilitation of the Istituto Auxologico Italiano Piancavallo (Verbania), Italy, all patients may be visited at least once per year. The visits included a clinical update via a neurological exam (UPDRS motor part) [12] and a neuropsychological battery, including Mini Mental State Examination [13], Frontal Assessment Battery [14], and the Neuropsychiatry Inventory Test [15].
Patients were retrospectively divided into two groups according to the results of the first study: with $\mathrm{VH}$ (VRVH, 6 patients) and without VH (WVRVH, 17 patients).

In the VRVH group, one patient had died and one had undergone deep brain stimulation surgery (but was still included in the follow-up); in the second group (WVRVH), four patients had died and two patients could not be found. Thus, 5 of the 6 patients in the VRVH group and 11 of the 17 patients in the WVRVH group completed the follow-up (Figure 1).

\section{Results}

While none of the patients in the WVRVH group presented any hallucination in their clinical history, all six patients of the VRVH group reported the appearance of VH during the course of their disease. Curiously, the dead patient in the first group developed VH during their clinical course, while the four dead patients of the second group did not.

Demographics and clinical characteristics of the groups at baseline and eight years later at the follow-up are shown in Table 2 and Figure 2.

In Table 3, the classification table by logistic regression shows no prediction of $\mathrm{VH}$ starting from neuropsychological tests, while in Table 4 all the variables out of the logistic regression equation are reported. From Table 3 it can be seen that the neuropsychological tests (also reported in Table 4) were not able to predict (based on the logistic regression) VH a priori, highlighting that only VR was able to make a prediction in this sense. In fact, according to neuropsychological tests, the logistic regression forecasted that no patients would report VH; however, during VR six patients incidentally described VH confirmed eight years later. This result makes how VR highlighted a phenomenon that cannot be predicted with standard neuropsychological tests evident.

\section{Discussion}

Even with the limited sample size in this study, we reported a correlation between complaining of $\mathrm{VH}$ during a VR immersion and further appearance of $\mathrm{VH}$ in the clinical picture.

This finding leads us to two relevant observations concerning VR technology: (1) it can potentially induce unwanted effects in PD patients; and (2) there are questions about its usefulness in predicting further development of $\mathrm{VH}$ in PD.

4.1. Visual Hallucinations as Unwanted Effects of Virtual Reality. To our knowledge, in the literature there are no reports of unwanted effects concerning VR sessions for PD patients; our findings seem to be in contrast with the increasing claims of usefulness of VR in the rehabilitation approach of these patients $[2-4,16]$.

One explanation is that most VR methodologies used in rehabilitation programs for PD are not immersive or projected-based systems that strongly reduce the sense of 


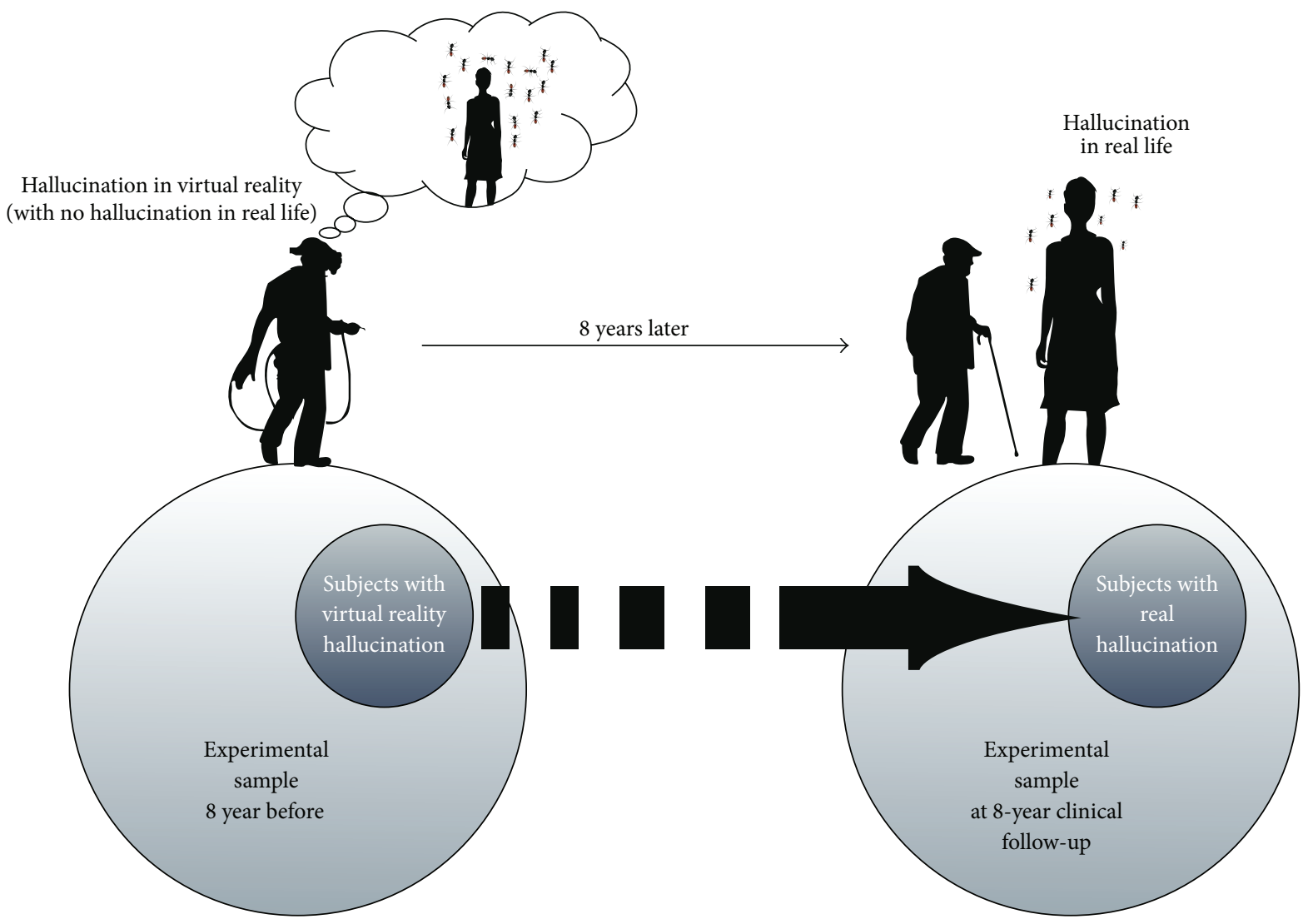

FIGURE 1: Experimental design.

TABLE 2: Demographics and clinical characteristics of groups at baseline and eight years later at follow-up.

\begin{tabular}{|c|c|c|c|}
\hline & VHVR (6) & WVHVR (17) & $P$ \\
\hline Age baseline & $67 \pm 7.5$ & $65 \pm 8.3$ & NS \\
\hline $\operatorname{Sex}(\mathrm{m})$ & 1 & 8 & NS \\
\hline Education & $8.5 \pm 3.8$ & $9.5 \pm 5.4$ & NS \\
\hline MMSE & $\begin{array}{c}\text { Baseline } 26.5 \pm 1.7 \\
\text { Follow-up } 23.2 \pm 3.3\end{array}$ & $\begin{array}{c}\text { Baseline } 25.6 \pm 2.9 \\
\text { Follow-up } 22.3 \pm 3.7\end{array}$ & $\begin{array}{l}\text { NS } \\
\text { NS }\end{array}$ \\
\hline Hoehn/Yahr stage & $\begin{array}{c}\text { Baseline } 2.8 \pm 1.5 \\
\text { Follow-up } 4 \pm 0\end{array}$ & $\begin{array}{c}\text { Baseline } 2.8 \pm 1.1 \\
\text { Follow-up } 3.1 \pm 0.7\end{array}$ & $\begin{array}{c}\text { NS } \\
P<0.005\end{array}$ \\
\hline UPDRS part III & $\begin{array}{l}\text { Baseline } 34.1 \pm 6.3 \\
\text { Follow-up } 51.2 \pm 7\end{array}$ & $\begin{array}{l}\text { Baseline } 34.9 \pm 14.4 \\
\text { Follow-up } 40.3 \pm 11\end{array}$ & $\begin{array}{c}\text { NS } \\
P<0.007\end{array}$ \\
\hline L-dopa eq/die (mg/day) & $\begin{array}{l}\text { Baseline } 683.3 \\
\text { Follow-up } 695 \\
\end{array}$ & $\begin{array}{c}\text { Baseline } 788 \\
\text { Follow-up } 633\end{array}$ & $\begin{array}{l}\text { NS } \\
\text { NS }\end{array}$ \\
\hline DA therapy (\%) & $\begin{array}{c}\text { Baseline } 100 \\
\text { Follow-up } 100\end{array}$ & $\begin{array}{c}\text { Baseline } 30 \\
\text { Follow-up } 70\end{array}$ & \\
\hline VH (\%) & $\begin{array}{c}\text { Baseline } 0 \\
\text { Follow-up } 100\end{array}$ & $\begin{array}{l}\text { Baseline } 0 \\
\text { Follow-up } 0\end{array}$ & \\
\hline NPI & $\begin{array}{c}\text { Baseline } 9.8 \pm 8.20 \\
\text { Follow-up } 13.8 \pm 7.8\end{array}$ & $\begin{array}{c}\text { Baseline } 6.8 \pm 5.8 \\
\text { Follow-up } 8.3 \pm 7.1\end{array}$ & $\begin{array}{l}\text { NS } \\
\text { NS }\end{array}$ \\
\hline FAB & $\begin{array}{c}\text { Baseline } 12.8 \pm 3 \\
\text { Follow-up } 11.4 \pm 2.3\end{array}$ & $\begin{array}{c}\text { Baseline } 14.6 \pm 2.7 \\
\text { Follow-up } 13.4 \pm 2.6\end{array}$ & $\begin{array}{l}P<0.04 \\
P<0.07\end{array}$ \\
\hline
\end{tabular}

All values represent mean (SD, when not otherwise stated).

MMSE = Mini Mental State Examination; NPI = Neuropsychiatry Inventory; FAB = Frontal Assessment Battery; UPDRS part III = Unified Parkinson’s Disease Rating Scale-subscale III; VH = visual hallucination in the real life. 

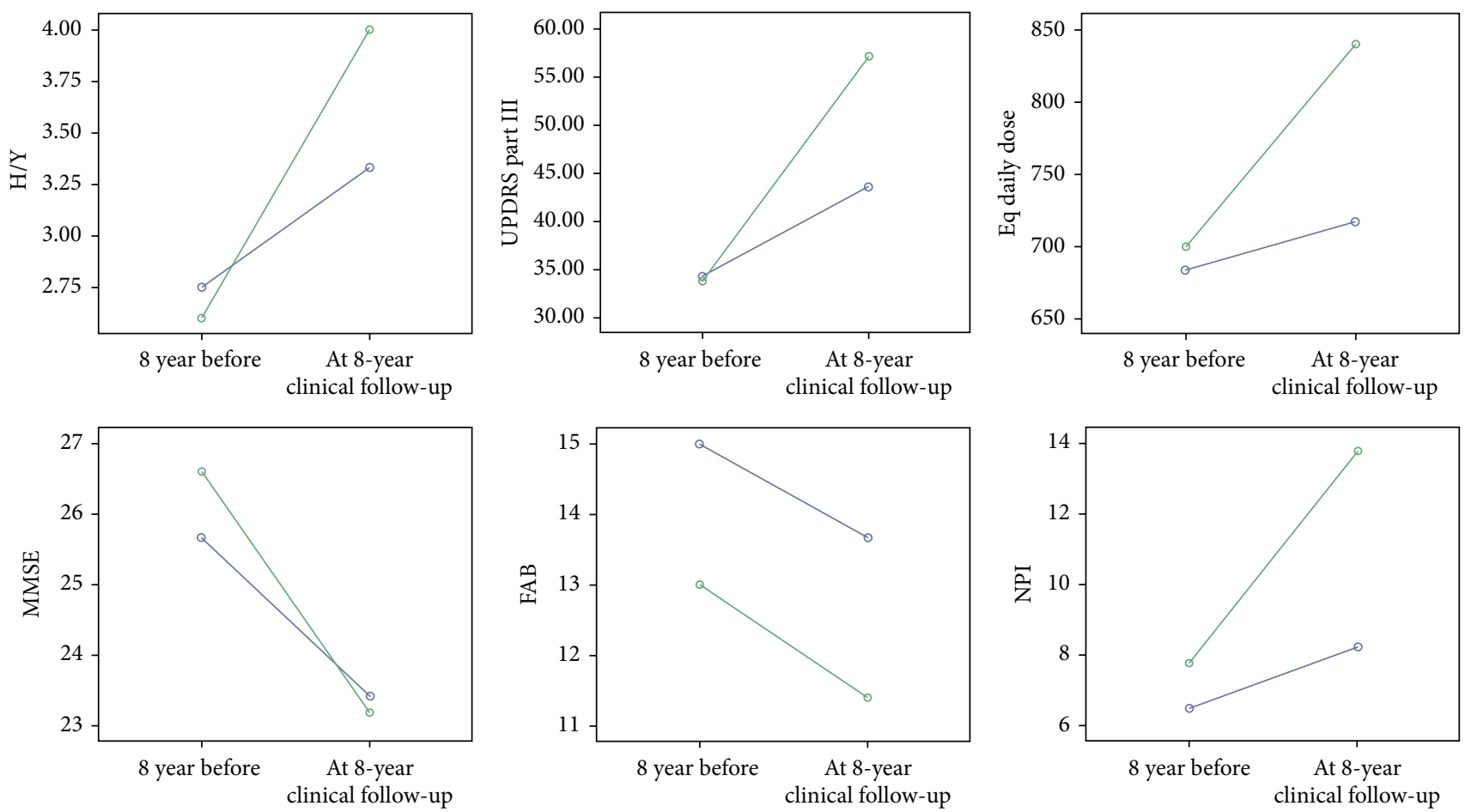

Visual hallucination $(\mathrm{VH})$ in virtual reality $(\mathrm{VR})$

- No virtual hallucination

— Virtual hallucination

Figure 2: All variables show that all the patients eight years later worsened, but even more so for the patients who experienced virtual hallucinations after eight years.

TABLE 3: Classification table by logistic regression showing no prediction of visual hallucination starting from neuropsychological tests.

\begin{tabular}{lccc}
\hline Observed & No virtual hallucination & $\begin{array}{c}\text { Predicted } \\
\text { Virtual hallucination }\end{array}$ & Percentage correct \\
\hline No virtual hallucination & 17 & 0 & 100.0 \\
Virtual hallucination & 6 & 0 & 0.0 \\
\hline
\end{tabular}

TABLE 4: Table showing that all the variables are not in the logistic regression equation.

\begin{tabular}{lcccc}
\hline & & Score & df. & Sig. \\
\hline \multirow{4}{*}{ Variables } & Education & .184 & 1 & .668 \\
& H/Y stage & .335 & 1 & .563 \\
& UPDRS part III & .017 & 1 & .895 \\
& Eq daily dose & .007 & 1 & .935 \\
& MMSE & .461 & 1 & .497 \\
& FAB & 2.837 & 1 & .092 \\
Overall statistics & NPI & 1.030 & 1 & .310 \\
\hline
\end{tabular}

presence, which may be considered a trigger for unwanted effects, especially those regarding the visual system.

VR experiences are pooled by a common step-simulation by the interaction [17]. One of the most critical features that differentiates immersive VR from nonimmersive VR is the sense of reality (better known as "sense of presence" among experts in cybertherapy), which means that the proband feels the virtual experience as real.

This feeling of presence, which in adult subjects is modulated by the prefrontal cortex-visual system loop [18], is strictly influenced by the sophistication of the used software.

4.2. Why Visual Hallucinations? Various pathogenic models have been considered to explain $\mathrm{VH}$ in $\mathrm{PD}$, such as the hypersensitivity of mesolimbic receptors due to dopaminergic denervation during a dopaminergic treatment [19], the deregulation of external perception and internal image production according to the dream imagery intrusion model [20], a deficit in reality monitoring [21], or a processing disruption across attentional networks [22].

$\mathrm{VH}$ are one of the most typical symptoms among the behavioural disturbances observed in $\mathrm{PD}$, affecting about one-quarter of patients. Several descriptions reported the presence of formed images as inanimate objects or 
indefinite/not fully formed images, sensation of presence (persons-guardian angel), or simply illusions consisting of the misinterpretation of images, with the overlap of humanoid or animal tracts on animated objects [23].

Curiously, VH can also include the feeling of an abnormal "presence" (a vague and erroneous perception that another person or threat is present) or "passage" hallucinations (transient undefined hallucinations that pass through the periphery of the visual field) [24].

The presence of VH during VR immersion is an interesting and unexpected finding, as few side effects following immersion in VR have been previously reported in literature. Research conducted on a group of healthy individuals evidenced transient reduced binocular vision after wearing a head-mounted display for just ten minutes [25], which was probably due to the generation of three-dimensional visual space from two-dimensional images. Nausea has been reported during 20-minute immersion periods and tenminute postimmersion periods, which has been attributed to the incongruity between visual and vestibular motion cues [26].

$\mathrm{VH}$ in VR navigation show similarities with $\mathrm{VH}$ usually evoked in the clinical history of PD patients, such as preserved awareness, only a moderate impact of stress, and the incidence of images resembling animals (three of six patients in the present study).

The VH shown by our patients always occurred only during "off-medication" periods.

Other authors [27] reported an impaired adaptation to visuomotor perturbations in VR environments during offstate, suggesting a hypofunctional state of the dopaminergic retinal system and reflecting the same "on-off" dependence alterations of visual abnormalities observed during recording by contrast sensitivity, electroretinograms, and visual evoked potentials in PD patients with motor fluctuations [16]. Furthermore, it was also shown that vision fluctuates in parallel with motor fluctuations [28]. Some authors also reported that $\mathrm{VH}$ tend to occur during times of low ambient stimulation, most typically in the evening or when the patient is alone in a quiet environment [29]. Finally, visual attention impairment has been described in patients with $\mathrm{VH}$ with acquired eye diseases [30].

We can argue that a reduced dopaminergic state is correlated with an altered sense of presence, such as that observed in children whose immature prefrontal brain structure would lead them to an increased susceptibility for the experience of presence [22]. Thus, as also reported by neurofunctional studies [31], a dysfunction of the frontal areas associated with the control of visual attention could predispose PD patients to $\mathrm{VH}$ through an abnormal processing of relevant and irrelevant visual stimuli.

\subsection{Visual Hallucinations as Prediction of Cognitive Impair-} ment. Various prospective studies $[11,32,33]$ have considered $\mathrm{VH}$ a risk factor for dementia. When examined longitudinally, VH affect more patients than is commonly assumed in cross-sectional prevalence studies. Neuropsychological and FDG-PET studies have demonstrated that visuoperceptual impairment and early involvement of the posterior neocortex may be risk factors for rapid symptomatic progression and dementia in PD [34].

In the present study, the comparison between the two groups shows that the L-dopa eq/die of the WVHVR patients is substantially lower at the baseline than in the follow-up, so that the Hoehn/Yahar stage and UPDRS part III score. These data would support the assumption that visual hallucinations, cognitive impairment, and motor scores seem to run in the same direction $[10,11]$.

However, our findings can only raise and not solve the question of whether VR technology can potentially be considered a useful tool to predict who could further develop $\mathrm{VH}$.

Indeed, our study is limited by the restricted number of cases and by the fact that a repetition of the VR session was not included in the clinical follow-up. Moreover, as the $\mathrm{VH}$ were an unexpected side effect at that time, visual performances (such as color discrimination and contrast perception) of all patients have not been investigated.

\section{Conclusions}

In consideration of the growing use of $\mathrm{VR}$ in $\mathrm{PD}$ treatment, the first intent of this paper is to alert the scientific community about the possibility of unwanted effects when immersive systems are used.

Moreover, we describe a link between past and further occurrence of VH in VR and clinical history, respectively, but only further controlled studies with larger numbers of cases will lead to the answers.

\section{Conflict of Interests}

The authors declare that there is no conflict of interests regarding the publication of this paper.

\section{References}

[1] L. Rochester, V. Hetherington, D. Jones et al., "The effect of external rhythmic cues (auditory and visual) on walking during a functional task in homes of people with Parkinson's disease," Archives of Physical Medicine and Rehabilitation, vol. 86, no. 5, pp. 999-1006, 2005.

[2] A. Mirelman, L. Rochester, M. Reelick et al., "V-TIME: a treadmill training program augmented by virtual reality to decrease fall risk in older adults: study design of a randomized controlled trial," BMC Neurology, vol. 13, article 15, 2013.

[3] H.-S. Park, J. W. Yoon, J. Kim, K. Iseki, and M. Hallett, "Development of a VR-based treadmill control interface for gait assessment of patients with Parkinson's disease," in Proceedings of the IEEE International Conference on Rehabilitation Robotics (ICORR '11), pp. 1-5, Zurich, Switzerland, July 2011.

[4] G. Frazzitta, R. Maestri, D. Uccellini, G. Bertotti, and P. Abelli, "Rehabilitation treatment of gait in patients with Parkinson's disease with freezing: a comparison between two physical therapy protocols using visual and auditory cues with or without treadmill training," Movement Disorders, vol. 24, no. 8, pp. 1139$1143,2009$.

[5] M. Ferrarin, M. Rabuffetti, M. Tettamanti, R. Pignatti, A. Mauro, and G. Albani, "Effect of optical flow versus attentional 
strategy on gait in Parkinson's Disease: a study with a portable optical stimulating device," Journal of NeuroEngineering and Rehabilitation, vol. 5, article 3, 2008.

[6] S. Badarny, J. Aharon-Peretz, Z. Susel, G. Habib, and Y. Baram, "Virtual reality feedback cues for improvement of gait in patients with Parkinson's disease," Tremor and Other Hyperkinetic Movements, vol. 4, article 225, 2014.

[7] G. Albani, F. Menegoni, C. Trotti, and A. Mauro, "Balance in virtual reality in Parkinson's disease: a preliminary study," Journal of Neurology, vol. 256, p. S144, 2009, Proceedings of the 19th Meeting of the European Neurological Society.

[8] M. Onofrj, L. Bonanni, G. Albani, A. Mauro, D. Bulla, and A. Thomas, "Visual hallucinations in Parkinson's disease: clues to separate origins," Journal of the Neurological Sciences, vol. 248, no. 1-2, pp. 143-150, 2006.

[9] G. Albani, G. Riva, D. Bulla et al., "Behaviour of motor disabilities and appearance of visual hallucinations in patients with Parkinson's disease in a virtual environment," Studies in Health Technology and Informatics, vol. 144, pp. 204-207, 2009.

[10] K. Bronnick, M. Emre, S. Tekin, S. B. Haugen, and D. Aarsland, "Cognitive correlates of visual hallucinations in dementia associated with Parkinson's disease," Movement Disorders, vol. 26, no. 5, pp. 824-829, 2011.

[11] K. Zhu, J. J. van Hilten, and J. Marinus, "Predictors of dementia in Parkinson's disease; findings from a 5-year prospective study using the SCOPA-COG," Parkinsonism \& Related Disorders, vol. 20, no. 9, pp. 980-985, 2014.

[12] C. C. Goetz, “The Unified Parkinson's Disease Rating Scale (UPDRS): status and recommendations," Movement Disorders, vol. 18, no. 7, pp. 738-750, 2003.

[13] E. Magni, G. Binetti, A. Bianchetti, R. Rozzini, and M. Trabucchi, "Mini-mental state examination: a normative study in Italian elderly population," European Journal of Neurology, vol. 3, no. 3, pp. 198-202, 1996.

[14] I. Appollonio, M. Leone, V. Isella et al., “The frontal assessment battery (FAB): normative values in an Italian population sample," Neurological Sciences, vol. 26, no. 2, pp. 108-116, 2005.

[15] J. L. Cummings, M. Mega, K. Gray, S. Rosenberg-Thompson, D. A. Carusi, and J. Gornbein, "The neuropsychiatric inventory: comprehensive assessment of psychopathology in dementia," Neurology, vol. 44, no. 12, pp. 2308-2314, 1994.

[16] K.-J. Su, W.-J. Hwang, C.-Y. Wu, J.-J. Fang, I.-F. Leong, and H.-I. $\mathrm{Ma}$, "Increasing speed to improve arm movement and standing postural control in Parkinson's disease patients when catching virtual moving balls," Gait and Posture, vol. 39, no. 1, pp. 65-69, 2014.

[17] G. Riva, "Is presence a technology issue? Some insights from cognitive sciences," Virtual Reality, vol. 13, no. 3, pp. 159-169, 2009.

[18] T. Baumgartner, D. Speck, D. Wettstein, O. Masnari, G. Beeli, and L. Jäncke, "Feeling present in arousing virtual reality worlds: prefrontal brain regions differentially orchestrate presence experience in adults and children," Frontiers in Human Neuroscience, vol. 2, article 8, 2008.

[19] M. Onofrj, M. F. Ghilardi, M. Basciani, and D. Gambi, "Visual evoked potentials in Parkinsonism and dopamine blockade reveal a stimulus-dependent dopamine function in humans," Journal of Neurology Neurosurgery and Psychiatry, vol. 49, no. 10, pp. 1150-1159, 1986.

[20] I. Arnulf, A.-M. Bonnet, P. Damier et al., "Hallucinations, REM sleep, and Parkinson's disease: a medical hypothesis," Neurology, vol. 55, no. 2, pp. 281-288, 2000.
[21] J. Barnes, L. Boubert, J. Harris, A. Lee, and A. S. David, "Reality monitoring and visual hallucinations in Parkinson's disease," Neuropsychologia, vol. 41, no. 5, pp. 565-574, 2003.

[22] J. M. Shine, G. M. Halliday, S. L. Naismith, and S. J. G. Lewis, "Visual misperceptions and hallucinations in Parkinson's disease: dysfunction of attentional control networks?" Movement Disorders, vol. 26, no. 12, pp. 2154-2159, 2011.

[23] M. F. Ghilardi, I. Bodis-Wollner, M. C. Onofrj, M. S. Marx, and A. A. Glover, "Spatial frequency-dependent abnormalities of the pattern electroretinogram and visual evoked potentials in a parkinsonian monkey model," Brain, vol. 111, no. 1, pp. 131-149, 1988.

[24] G. Fénelon, F. Mahieux, R. Huon, and M. Ziégler, "Hallucinations in Parkinson's disease: prevalence, phenomenology and risk factors," Brain, vol. 123, no. 4, pp. 733-745, 2000.

[25] M. A. Mon-Williams, J. P. Wann, S. K. Rushton, and R. Ackerley, "Real problems with virtual worlds," Ophthalmic and Physiological Optics, vol. 13, pp. 435-436, 1993.

[26] C. Regan, "An investigation into nausea and other side-effects of head-coupled immersive virtual reality," Virtual Reality, vol. 1, no. 1, pp. 17-31, 1995.

[27] D. Mongeon, P. Blanchet, and J. Messier, "Impact of Parkinson's disease and dopaminergic medication on adaptation to explicit and implicit visuomotor perturbations," Brain and Cognition, vol. 81, no. 2, pp. 271-282, 2013.

[28] I. Bodis-Wollner, "Visual deficits related to dopamine deficiency in experimental animals and Parkinson's disease patients," Trends in Neurosciences, vol. 13, no. 7, pp. 296-302, 1990.

[29] B. Ravina, K. Marder, H. H. Fernandez et al., "Diagnostic criteria for psychosis in Parkinson's disease: report of an NINDS, NIMH Work Group," Movement Disorders, vol. 22, no. 8, pp. 1061-1068, 2007.

[30] G. Graham, J. Dean, U. P. Mosimann et al., "Specific attentional impairments and complex visual hallucinations in eye disease," International Journal of Geriatric Psychiatry, vol. 26, no. 3, pp. 263-267, 2011.

[31] B. Ramírez-Ruiz, M.-J. Martí, E. Tolosa et al., "Brain response to complex visual stimuli in Parkinson's patients with hallucinations: a functional magnetic resonance imaging study," Movement Disorders, vol. 23, no. 16, pp. 2335-2343, 2008.

[32] D. Aarsland, K. Andersen, J. P. Larsen, A. Lolk, and P. Kragh-Sørensen, "Prevalence and characteristics of dementia in Parkinson disease: an 8-year prospective study," Archives of Neurology, vol. 60, no. 3, pp. 387-392, 2003.

[33] R. B. Postuma, J.-A. Bertrand, J. Montplaisir et al., "Rapid eye movement sleep behavior disorder and risk of dementia in Parkinson's disease: a prospective study," Movement Disorders, vol. 27, no. 6, pp. 720-726, 2012.

[34] Y. Shoji, Y. Nishio, T. Baba et al., "Neural substrates of cognitive subtypes in Parkinson's disease: a 3-year longitudinal study," PLoS ONE, vol. 9, no. 10, Article ID e110547, 2014. 


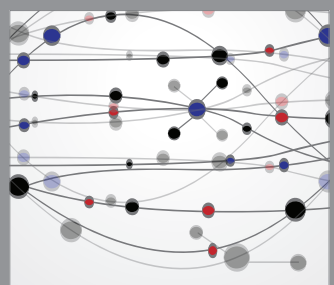

The Scientific World Journal
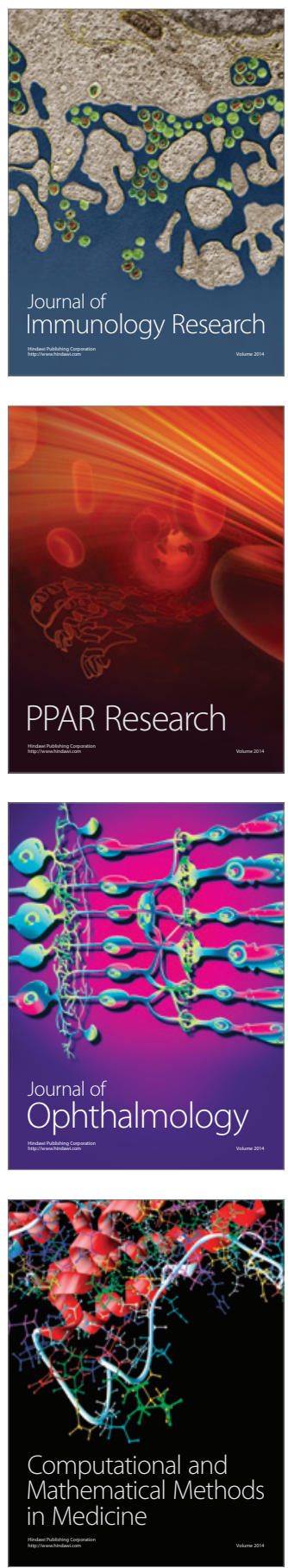

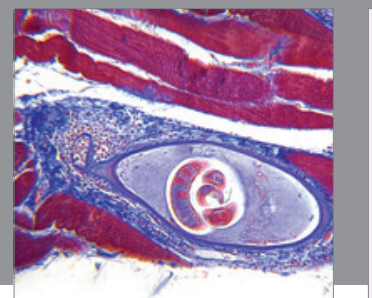

Gastroenterology

Research and Practice
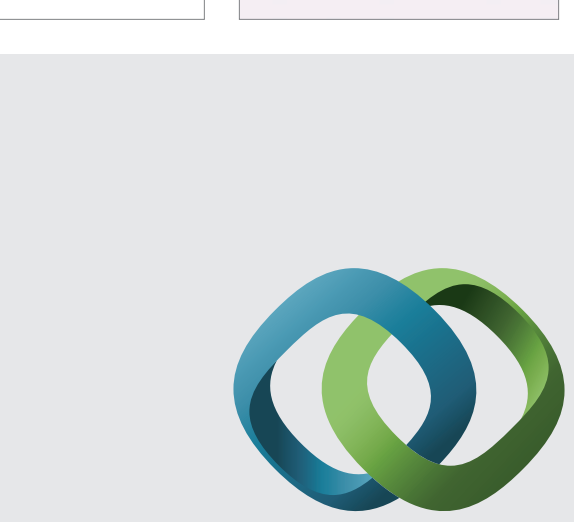

\section{Hindawi}

Submit your manuscripts at

http://www.hindawi.com
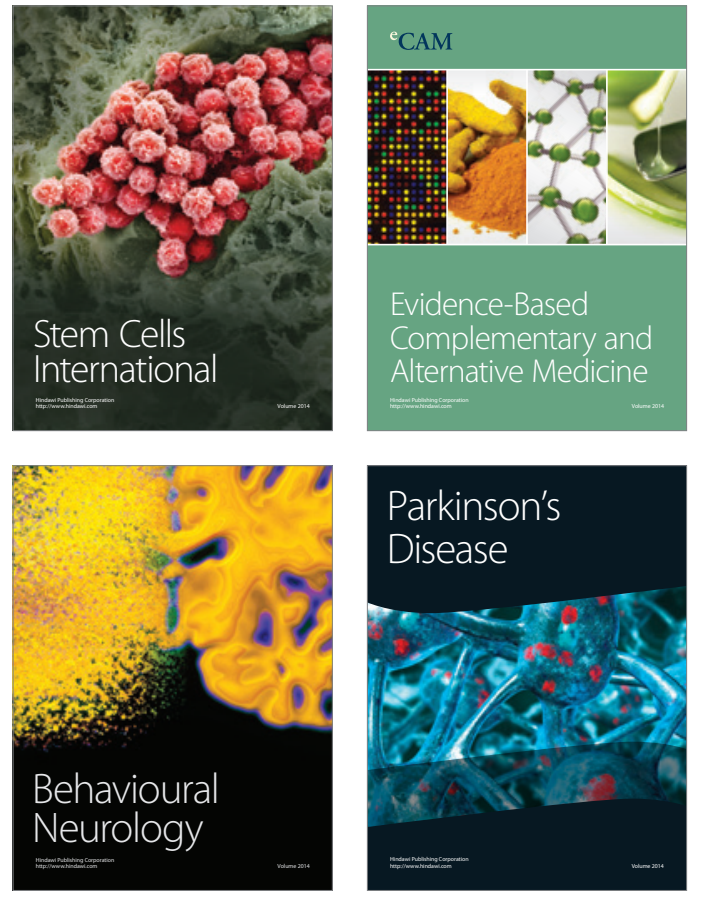
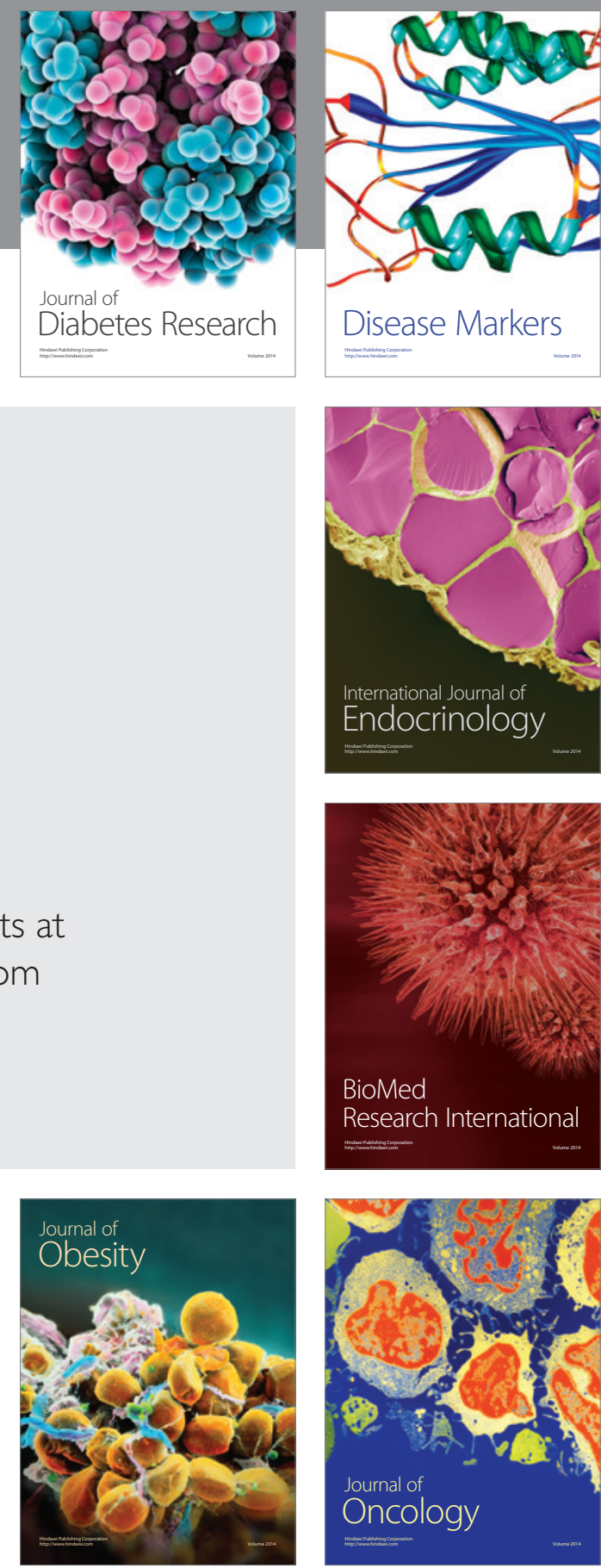

Disease Markers
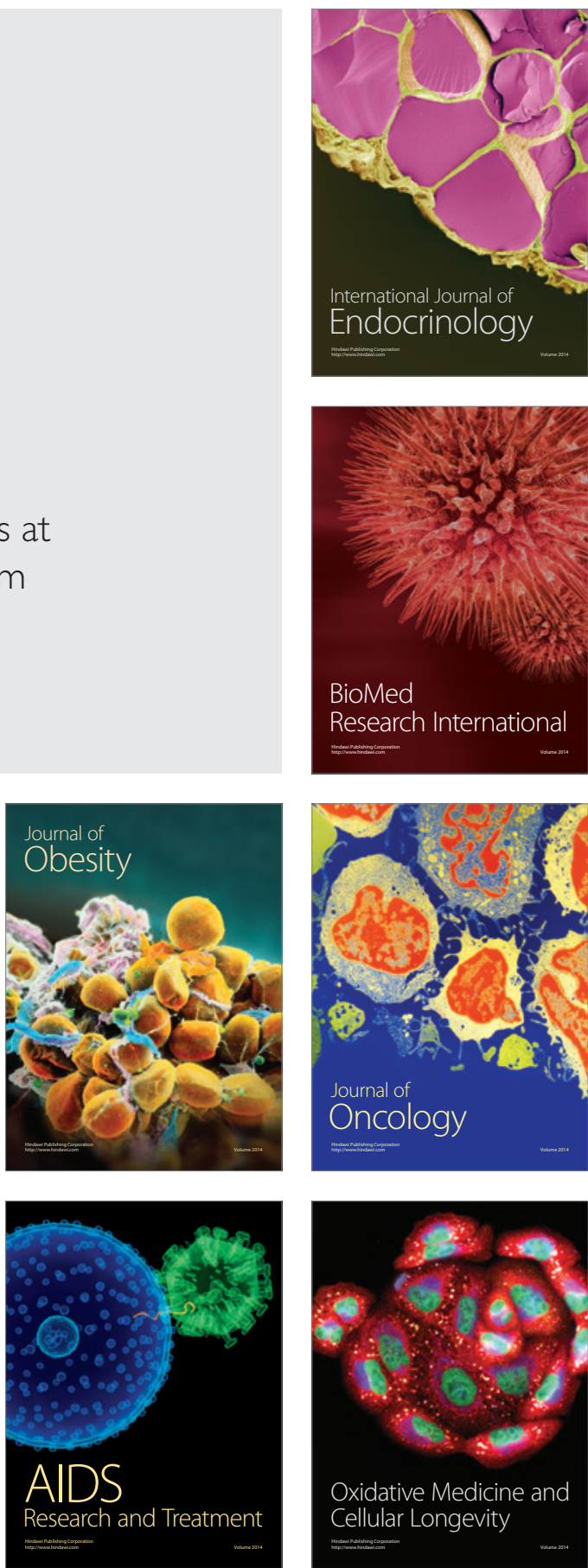